\title{
Mechanisms of Mid-Holocene Precipitation Change in the South Pacific Convergence Zone
}

\author{
Damianos F. Mantsis, Benjamin R. Lintner, And Anthony J. Broccoli \\ Rutgers, The State University of New Jersey, New Brunswick, New Jersey \\ MYRIAM KHODRI \\ Laboratoire d'Océanographie et du Climat, IPSL, Paris, France
}

(Manuscript received 17 September 2012, in final form 5 March 2013)

\begin{abstract}
The variability of the South Pacific convergence zone (SPCZ) during the mid-Holocene is investigated using models archived in the Paleoclimate Modelling Intercomparison Project Phase II (PMIP2) database. Relative to preindustrial conditions, mid-Holocene top-of-atmosphere insolation was relatively lower during austral summer [December-February (DJF)], which is the season when the SPCZ is at its peak intensity. In response to this perturbation, the PMIP2 models simulate a displacement of the SPCZ to the southwest. This SPCZ shift is associated with a sea surface temperature (SST) dipole, with increased rainfall collocated with warm SST anomalies. Decomposing the DJF precipitation changes in terms of a diagnostic moisture budget indicates that the SPCZ shift is balanced to leading order by a change in the mean moisture convergence. Changes to the broad area of upper-level negative zonal stretching deformation, where transient eddies can become trapped and subsequently generate deep convection, support the notion that the SPCZ shift in the subtropics is tied to eddy forcing. Idealized experiments performed with an intermediate-level complexity model, the Quasi-Equilibrium Tropical Circulation Model (QTCM), suggest that the mid-Holocene change in rainfall in the SPCZ region as well as the equatorial Pacific is dominated by a change in the underlying SST. The tropical portion of the SPCZ is further remotely affected by the orbitally induced weakening of the Australian monsoon, even though this effect is weaker compared to the effect from SSTs.
\end{abstract}

\section{Introduction}

a. Theories on the South Pacific convergence zone in current climate

The Pacific supports Earth's most extensive region of tropical deep convection, which extends eastward from the west Pacific warm pool as the intertropical convergence zone (ITCZ) and diagonally to the southeast as the South Pacific convergence zone (SPCZ) (Trenberth 1976; Kodama 1992, 1993; Vincent 1994; Cai et al. 2012; Matthews 2012; Widlansky et al. 2013). The SPCZ itself stretches from the equator to Southern Hemisphere (SH) midlatitudes and peaks in intensity during austral summer [December-February (DJF)]. In fact, the SPCZ is associated with one of Earth's most persistent bands of

Corresponding author address: Damianos F. Mantsis, Department of Environmental Sciences, Rutgers, The State University of New Jersey, 14 College Farm Rd., New Brunswick, NJ 08901-8551.

E-mail: dmantsis@envsci.rutgers.edu precipitation and cloudiness and plays a significant role in Earth's energy budget as well as atmospheric and oceanic circulation (Vincent 1994).

Precipitation in the SPCZ appears to depend on multiple tropical and extratropical processes varying on many time scales in the current climate, for example, SH midlatitude storms on synoptic time scales, the Madden-Julian oscillation (MJO) on intraseasonal time scales, and the El Niño-Southern Oscillation (ENSO) on interannual time scales (Salinger et al. 1995; Folland et al. 2002; Matthews 2012; Cai et al. 2012). Moreover, as inferred from both instrumental observations (Folland et al. 2002) and oxygen isotope proxy records from coral reefs (Delcroix et al. 2007; Linsley et al. 2008), the SPCZ appears to be correlated on decadal time scales with largescale modes such as the interdecadal Pacific oscillation (IPO), with the SPCZ shifting to the northeast when the western Pacific warm pool warms and expands eastward.

The tropical component of the climatological SPCZ, which is anchored over the western Pacific warm pool, is 
tied to the high SSTs (Kiladis et al. 1989; von Storch et al. 1988) and low-level convergence induced by the SST gradient between the warm pool and the equatorial cold tongue (Lindzen and Nigam 1987; Cai et al. 2012). Within the tropical portion of the climatological SPCZ, eastward propagating convectively coupled waves (MJO) account for a large fraction of the precipitation (Matthews and Li 2005). Low-level dry air advection associated with southeasterly trade wind inflow limits the eastern extent of SPCZ region deep convection (Lintner and Neelin 2008).

The Australian monsoon has also been implicated in the formation of the SPCZ: according to Kiladis et al. (1989) the continental summertime monsoonal heat low over Australia creates a region of convergence that extends eastward and contributes to the precipitation on the western flank of the SPCZ. An idealized aquaplanet study by Kodama (1999) suggests that off-equatorial atmospheric heat sources of monsoonal origin can maintain diagonal subtropical convergence zones resembling the SPCZ. This is accomplished through convergence of poleward moisture flux, which itself is maintained by a diabatic heating-induced low-level trough and an upperlevel jet.

In contrast to the SPCZ's tropical portion, its subtropical to midlatitude portion appears to be associated with a low-level trough and an upper-level ridge system tilting both poleward and westward, implying high baroclinicity (Trenberth 1976; Vincent 1994; Kiladis et al. 1989). The baroclinic nature of the diagonal part of the SPCZ implicates midlatitude eddies as a source of precipitation in this region. Eddies moving to the east of Australia enter an area where the upper-level subtropical jet decelerates to the east (i.e., $\partial \bar{u} / \partial x<0$ ), resulting in an area of negative zonal stretching deformation that may trap eddies (Trenberth 1976). The negative zonal stretching deformation promotes a decrease in eddy wavenumber and an increase of associated energy density, which in turn may trigger deep convection (Widlansky et al. 2011; Matthews 2012). Modes of intraseasonal or interannual variability may influence the contribution of eddies to the SPCZ by altering the mean background state within which eddies propagate (Matthews 2012).

Given the myriad climate processes operating in the SPCZ region, it is not surprising that the mechanisms controlling SPCZ structure and variability are not completely understood. Although most of the Coupled Model Intercomparison Project (CMIP) models used in either the Intergovernmental Panel on Climate Change (IPCC) Fourth or Fifth Assessment Reports (CMIP3 and CMIP5, respectively) simulate a distinct SPCZ, these models reflect a large spread in terms of its intensity, slope, position (which in most cases differs markedly from observations; Lin 2007; Brown et al. 2011, 2013), and variability (Cai et al. 2009). Among the 24 CMIP3 models examined in Brown et al. (2011), only a few simulate the spatial characteristics of the SPCZ accurately, with the underestimation of the SPCZ slope (defined here as the northwest to southeast orientation of the SPCZ) representing a common bias that results in a far too zonally oriented SPCZ. This bias may contribute to the wellknown "double Pacific ITCZ" problem and needs to be taken into account when interpreting climate change scenarios in the SPCZ region. The incorrect spatial structure of the simulated SPCZ may be related to known biases in coupled model simulation of tropical Pacific SSTs (Dai 2006; Lin 2007).

\section{b. Overview of mid-Holocene orbital forcing and its relationship to tropical convection}

The present study focuses on the fundamental processes contributing to the SPCZ variability on millennial time scales, for which the mid-Holocene (6000 years before present, hereafter $6 \mathrm{kyr} \mathrm{BP}$ ) represents an ideal test bed. During the mid-Holocene, greenhouse gases and ice sheets were comparable with conditions during the preindustrial period; on the other hand, mid-Holocene climate differed from the preindustrial because of differences in orbital parameters. The principal orbital parameters in the standard Milankovich theory are the longitude of the perihelion, obliquity, and eccentricity. The principal signatures of the mid-Holocene change in the top-of-atmosphere (TOA) insolation are strengthening in Northern Hemisphere (NH) summer and weakening in $\mathrm{NH}$ winter, causing an overall strengthening of $\mathrm{NH}$ seasonality (Fig. 1). In contrast, in the $\mathrm{SH}$, local summer (DJF) insolation decreases and the local winter [June-August (JJA)] insolation increases, which results in a weakening of the seasonality. Such insolation change may be anticipated to have a large impact on SH tropical precipitation during DJF, when the SPCZ is at its climatological maximum intensity and spatial extent.

Continental precipitation proxies from the tropics largely show that convective activity at low latitudes is dominated by changes in the longitude of the perihelion, called precessional cycles. Oxygen isotope $\left(\delta^{18} \mathrm{O}\right)$ measurements extracted from stalagmites from caves in southeast China (Wang et al. 2008) indicate that the East Asian summer monsoon (EASM) has varied in phase with precessional forcing of $\mathrm{NH}$ summer insolation, with a more intense, wetter summertime monsoon at midHolocene. Other NH monsoon systems exhibit similar variability. Proxy records of lake and deep sea sediments from Africa and the east tropical Atlantic respectively show the strength of the Northern African summer monsoon varying in phase with Earth's precession (Partridge 


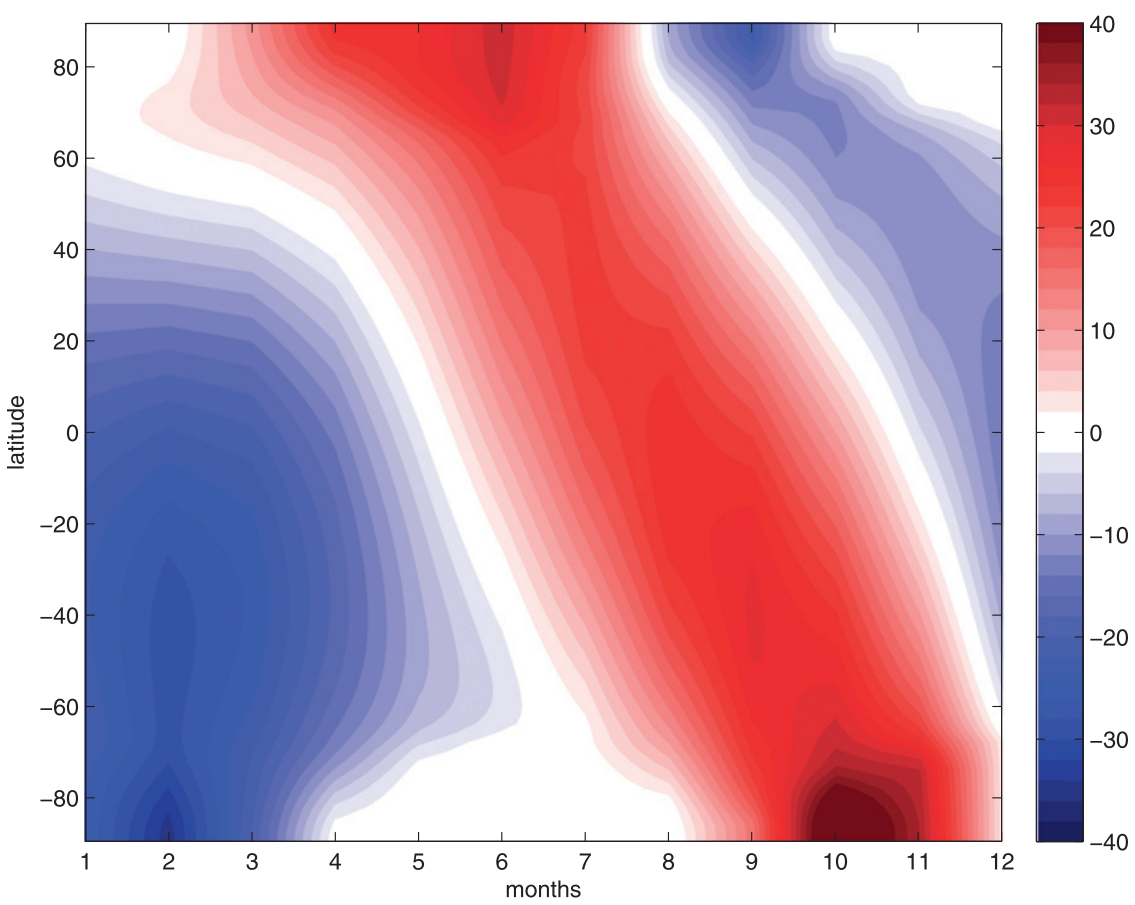

FIG. 1. Change (mid-Holocene minus preindustrial) in the seasonal cycle of the TOA insolation $\left(\mathrm{W} \mathrm{m}^{-2}\right)$ as a function of latitude.

et al. 1997), with this monsoon system stronger during the mid-Holocene. This is further supported by fossilized pollen-based reconstructions of vegetation from northern Africa that show that the Sahara desert was reduced in size during the mid-Holocene (Jully et al. 1998; Haibin et al. 2007). Additionally, $\mathrm{Ti}$ and $\mathrm{Fe}$ concentrations in river discharge sediments from the Cariaco Basin (Peterson and Haug 2006) show that precipitation over northern tropical South America was also increased during the mid-Holocene. By contrast, the orbital-scale variability of the $\mathrm{SH}$ monsoons is out of phase with the monsoons in the $\mathrm{NH}$ : the available paleoproxies indicate that monsoon systems in South America (Cruz et al. 2005) and southern Africa (Partridge et al. 1997) achieve maximum strength when $\mathrm{NH}$ monsoons are weakest and minimum strength when $\mathrm{NH}$ monsoons are strongest. Thus, $\mathrm{SH}$ monsoonal systems were weakened during the mid-Holocene.

Given its midoceanic location, precipitation proxies directly for SPCZ region are rather sparse. However, those proxies that are available do broadly indicate a rainier western Pacific and a drier eastern Pacific during the mid-Holocene (Fig. 2). For example, proxies based on pollen and limnological conditions from Efaté Island $\left(17^{\circ} 40^{\prime} \mathrm{S}, 168^{\circ} 20^{\prime} \mathrm{E}\right)$ located close to the present-day SPCZ point to enhanced precipitation at $6 \mathrm{kyr}$ BP (Wirrmann et al.2011). New Guinea, which is located in the tropical SPCZ, was also wetter during the mid-Holocene according to pollen and microcharcoal proxy records (Haberle 1998). In the south, sediment cores from New Zealand show that the southern edge of the SPCZ experienced increased storminess during the mid-Holocene (Gomez et al. 2004).

On the other hand, sedimentary lake records from Easter Island indicate that the eastern Pacific, which today is much drier compared to the western Pacific, was even drier during the mid-Holocene (Saez et al. 2009). Further to the east, arid mid-Holocene conditions prevailed over the west coast of Chile as suggested by a synthesis of proxies by Carre et al. (2012). This is further supported by salt and lacustrine mud depositions on the Bolivian Altiplano $\left(15^{\circ}-20^{\circ} \mathrm{S}\right)$, with drier conditions during the mid-Holocene (Jomelli et al. 2011), followed by a gradual increase in precipitation during the later Holocene (Baker et al. 2001).

Comparisons with both atmosphere-only and coupled general circulation models (GCMs) broadly reflect the mid-Holocene precipitation changes inferred from proxies, with a weakening of the Southern Hemisphere monsoons due to reduced local summer insolation, and ocean feedbacks acting in order to weaken this response (Zhao and Harrison 2012). In one particular model [Fast Ocean Atmosphere Model (FOAM)], the positive feedback from the ocean even overwhelms the negative effect of the reduced insolation, and the Australian monsoon appears to be slightly stronger during the mid-Holocene 


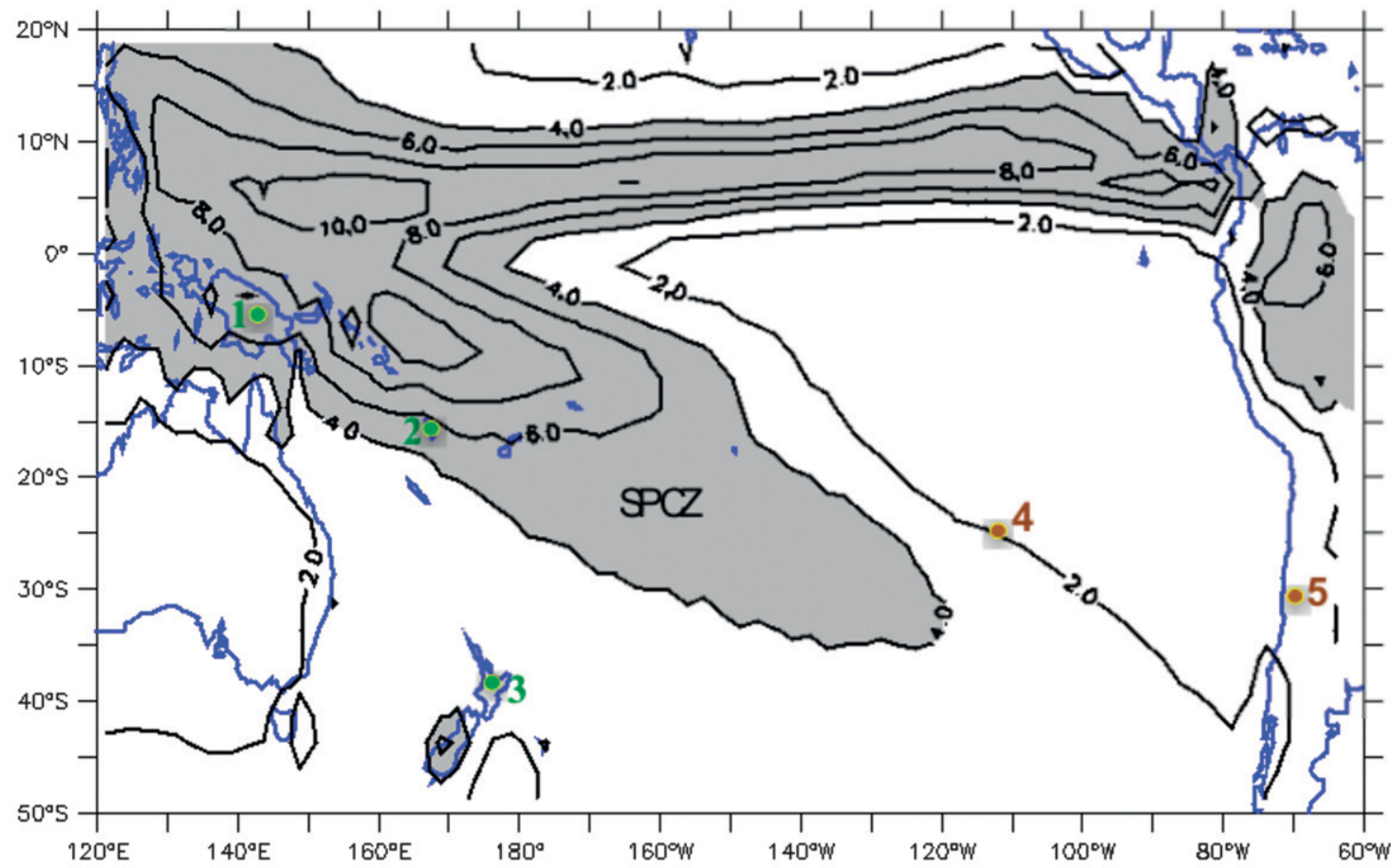

1. Pollen and microcharcoal, New Guinea [Haberle 1998]

2. Emaotfer Swamp multiproxies, Vanuatu [Wirrmann et al. 2011]

4. Raraku Lake sediments, Easter Island [Saez et al. 2009]

5. Multiproxy synthesis, central Andes [Carre et al, 2011]

3. Grain size, North Island, New Zealand [Gomez et al. 2004]

FIG. 2. Modern-day climatological annual-mean precipitation $\left(\mathrm{mm} \mathrm{day}^{-1}\right)$ in the Pacific basin. Data are from the Climate Prediction Center Merged Analysis of Precipitation (CMAP; Xie and Arkin 1997). Green (brown) circles represent proxy sites exhibiting wetter (drier) conditions during the mid-Holocene. Shaded areas with contours are for precipitation $>4.0$ ????.

compared to present day (Liu et al. 2004; Marshall and Lynch 2006; Zhao and Harrison 2012). Wyrwoll et al. (2007) have shown that the summer Australian monsoon can be influenced by factors other than direct orbital forcing, such as changes in outflow from the Northern Hemisphere Asian monsoon. A study by Hsu et al. (2010) using the same intermediate-level complexity model as in the present study [the Quasi-Equilibrium Tropical Circulation Model (QTCM); see Neelin and Zeng 2000; Zeng et al. 2000] agrees with the simulated mid-Holocene precipitation changes by GCMs, namely a weakening of SH monsoons and a southwestward shift of the SPCZ during DJF.

In the present study, we investigate whether an analogous relationship can be found between the changing SPCZ and the Australian monsoon. We begin by describing the climate models and methods used in this study (section 2). Section 3 documents the SPCZ region climate response to mid-Holocene insolation forcing in a subsample of Paleoclimate Modelling Intercomparison Project Phase II (PMIP2) models as well as the Geophysical Fluid Dynamics Laboratory (GFDL) model. With these models, we then perform a diagnostic moisture budget analysis (section 4). In section 5, we describe simulations performed with QTCM that are designed to isolate the mechanisms controlling the changes in the SPCZ. Section 6 summarizes these results and discusses their relevance to understanding what controls the modern-day SPCZ.

\section{Models and simulation design}

To understand the mechanisms controlling changes in SPCZ precipitation between preindustrial and midHolocene conditions, we analyze here a suite of models archived in the PMIP2 database (Braconnot et al. 2007). For each model we use two simulations. The first corresponds to the mid-Holocene climate, and the second corresponds to the preindustrial climate. The two simulations differ on the orbital parameters, with the longitude of the perihelion experiencing the largest change. On the other hand, changes in obliquity and eccentricity are relatively small. Greenhouse gases are slightly different between the two simulations and are not expected to contribute to the climate response. Other parameters (i.e., coastlines and ice sheets) are the same in both simulations.

Using the available models we perform a moisture budget analysis using pressure-level specific humidity 
TABLE 1. Models included in the ensemble mean diagnostic analysis. All models can be found at the PMIP2 website, except the GFDL CM2.1.

\begin{tabular}{|c|c|c|}
\hline Model & Model expansion & Resolution \\
\hline UBRIS-HadCM3M2 & $\begin{array}{l}\text { University of Bristol Hadley Centre Coupled Model, version 3, with land } \\
\text { surface scheme MOSES2 }\end{array}$ & $3.8^{\circ} \times 2.5^{\circ}$ \\
\hline CSIRO-Mk3L-1.0 & $\begin{array}{l}\text { Commonwealth Scientific and Industrial Research Organisation Mark, } \\
\text { version 3.0-low resolution, version } 1.0\end{array}$ & $5.6^{\circ} \times 3.2^{\circ}$ \\
\hline CSIRO-Mk3L-1.1 & $\begin{array}{l}\text { Commonwealth Scientific and Industrial Research Organisation Mark, version 3.0-low } \\
\text { resolution, version } 1.1\end{array}$ & $5.6^{\circ} \times 3.2^{\circ}$ \\
\hline CCSM3.0 & Community Climate System Model, version 3.0 & $2.8^{\circ} \times 2.8^{\circ}$ \\
\hline MIROC3.2 (medres) & Model for Interdisciplinary Research on Climate, version 3.2 (medium resolution) & $2.8^{\circ} \times 2.8^{\circ}$ \\
\hline MRI-CGCM2.3.4fa & $\begin{array}{l}\text { Meteorological Research Institute Coupled Atmosphere-Ocean General Circulation } \\
\text { Model, version 2.3.4, flux adjusted }\end{array}$ & $2.8^{\circ} \times 2.8^{\circ}$ \\
\hline MRI-CGCM2.3.4nfa & $\begin{array}{l}\text { Meteorological Research Institute Coupled Atmosphere-Ocean General Circulation } \\
\text { Model, version 2.3.4, nonflux adjusted }\end{array}$ & $2.8^{\circ} \times 2.8^{\circ}$ \\
\hline IPSL-CM4-V1-MR & L'Institut Pierre-Simon Laplace Coupled Model, version 4-mid resolution, version 1 & $3.8^{\circ} \times 2.5^{\circ}$ \\
\hline GISSmodelE & Goddard Institute for Space Studies Model E & $4^{\circ} \times 5^{\circ}$ \\
\hline FGOALS-g1.0 & Flexible Global Ocean-Atmosphere-Land System Model gridpoint, version 1.0 & $2.8^{\circ} \times 2.8^{\circ}$ \\
\hline ECHAM53-MPIOM127-LPJ & ECHAM53-Max Planck Institute Ocean Model 127-Lund-Potsdam-Jena & $3.8^{\circ} \times 3.7^{\circ}$ \\
\hline GFDL CM2.1 & Geophysical Fluid Dynamics Laboratory Climate Model, version 2.1 & $2^{\circ} \times 2.5^{\circ}$ \\
\hline
\end{tabular}

and wind. Given that some of the archived models do not include such data, and some models further appear to have inconsistent data, only the 11 PMIP2 models listed in Table 1 are analyzed here. Additionally, we analyze simulations performed with the GFDL Coupled Model, version 2.1 (CM2.1; Delworth et al. 2006). While GFDL CM2.1 is not included in the PMIP2 archive, the simulations included below were performed according to PMIP2 protocols. Use of the GFDL CM2.1 is motivated by the availability of daily data, which permits explicit investigation of high-frequency contributions to the moisture budget.

We also employ QTCM to test several hypotheses regarding controls on the mid-Holocene SPCZ changes. QTCM invokes the concept of quasi-equilibrium in which deep convection essentially maintains temperature and moisture profiles close to prescribed statistical equilibrium profiles. The prescribed vertical basis functions of temperature and moisture are obtained from observed soundings in regions of tropical deep convection, following from the observations that the tropical atmosphere is nearly moist adiabatic. For a specified temperature basis function under the assumption of hydrostatic balance, velocity basis functions are designed in such a way to be consistent with the implied barotropic and baroclinic pressure gradients. Together, the thermodynamic and dynamic basis functions are used to project the primitive equations in the vertical, so that QTCM solves prognostic equations in the horizontal dimensions only. The model version used here, QTCM1v2.3, contains one mode for each of temperature, moisture, and barotropic and baroclinic velocity modes. The horizontal resolution is $5.6^{\circ} \times 3.7^{\circ}$ with the latitudinal domain extending from $78^{\circ} \mathrm{S}$ to $78^{\circ} \mathrm{N}$. While QTCM is explicitly implemented for the tropics, we note that it does produce some aspects of extratropical climate (e.g., storm tracks; Zeng et al. 2000).

The QTCM simulations consist of both prescribed SST and coupled atmosphere-slab ocean model simulations. For the prescribed SST simulations, the SST forcing is obtained from the ensemble mean of the PMIP2 models. For the slab ocean version, a constant 50-m mixed layer is assumed and a $Q$ flux is applied to prevent climate drift. The prescribed $Q$ flux is estimated from a 10-yr run with prescribed climatological SSTs (Reynolds dataset; Reynolds and Smith 1994).

\section{Overview of mid-Holocene climate change in PMIP2 models}

Mid-Holocene tropical DJF precipitation, as simulated by the PMIP2 models, differs substantially from preindustrial conditions (Fig. 3), with strongly contrasting changes occurring over land and ocean. The PMIP2 ensemble mean exhibits an overall reduction of austral summer continental convective precipitation, associated with a weakening of the monsoons over Africa, South America, and Australia. On the other hand, DJF precipitation over tropical oceans is generally enhanced, although some regions (e.g., the equatorial Pacific and the northeast part of the SPCZ) experience reduced precipitation. The Indian Ocean experiences the largest anomalies with a general increase in precipitation over the basin. In the Atlantic Ocean, the ITCZ is displaced to the south at $6 \mathrm{k} \mathrm{yr} \mathrm{BP}$, with anomalies more pronounced to the east. In the Pacific, the largest changes are 


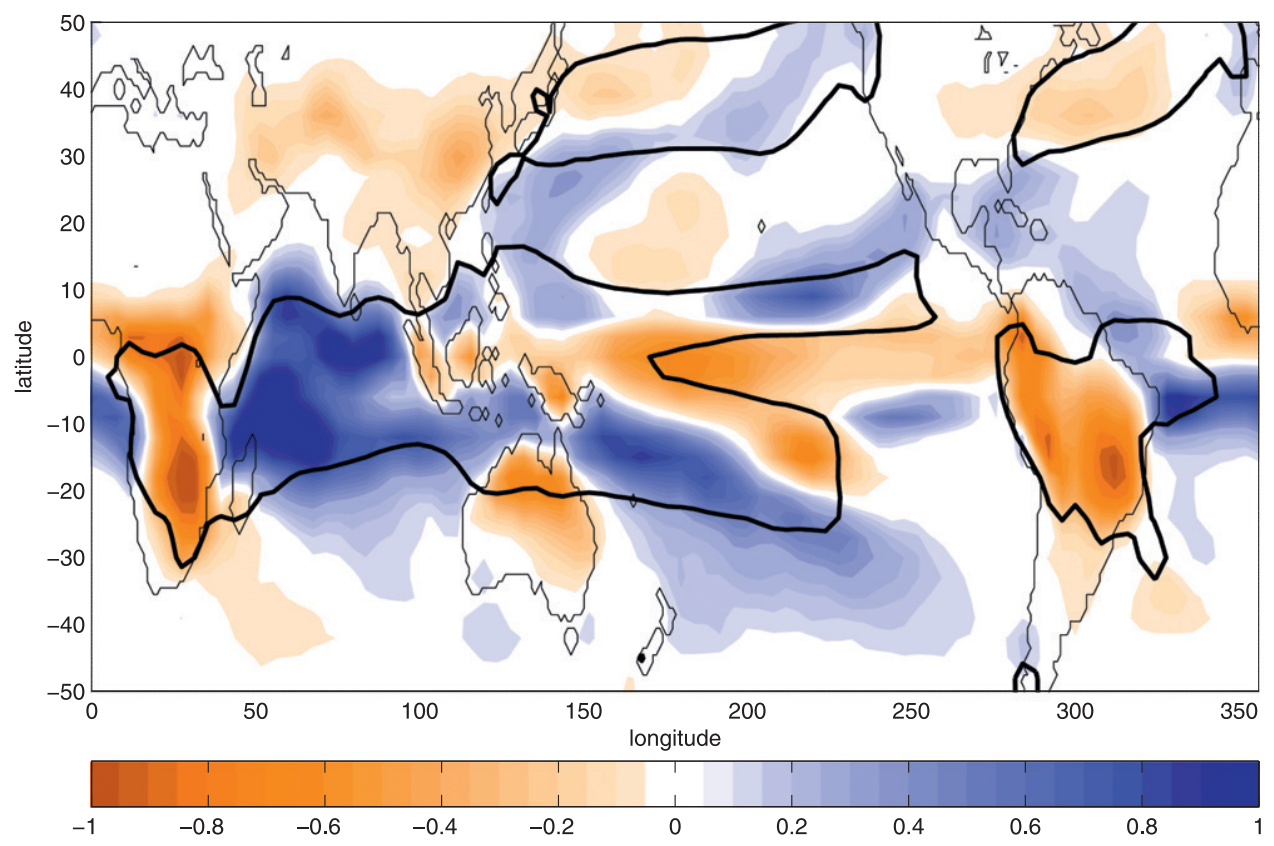

FIG. 3. PMIP2 ensemble-mean mid-Holocene minus preindustrial precipitation $\left(\mathrm{mm} \mathrm{day}^{-1}\right)$ for DJF. Values $>1 \mathrm{~mm}$ day $^{-1}\left(<-1 \mathrm{~mm} \mathrm{day}^{-1}\right)$ have colors that have been saturated. The thick black line represents the $4 \mathrm{~mm}$ day $^{-1}$ climatology contour (preindustrial) based on the PMIP2 ensemble mean.

associated with a southwestward shift of the SPCZ, which is the primary focus of this study. This shift is approximately parallel to the main axis of the modeled SPCZ and extends from the tropics to midlatitudes. The
SPCZ shift, as well as the weakening of the Australian monsoon, appears to be rather robust among the models examined, as these show widespread agreement (Fig. 4). However, it should be noted that among the 11 models

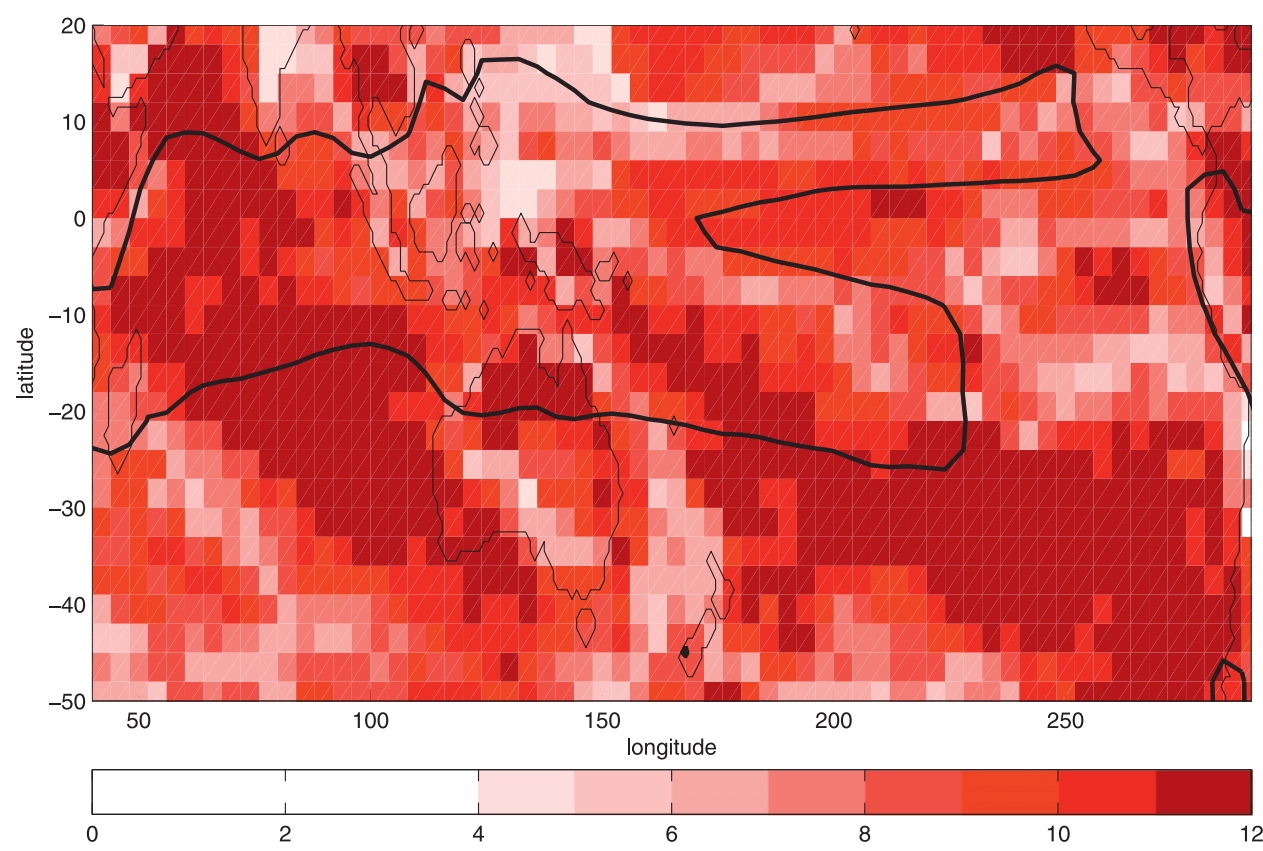

FIG. 4. PMIP2 model spread. Colors represent the number of models that agree with the sign of the ensemble-mean precipitation change (mid-Holocene minus preindustrial). The thick black line represents $4 \mathrm{~mm} \mathrm{day}^{-1}$ climatology contour (preindustrial) based on the PMIP2 ensemble mean. 

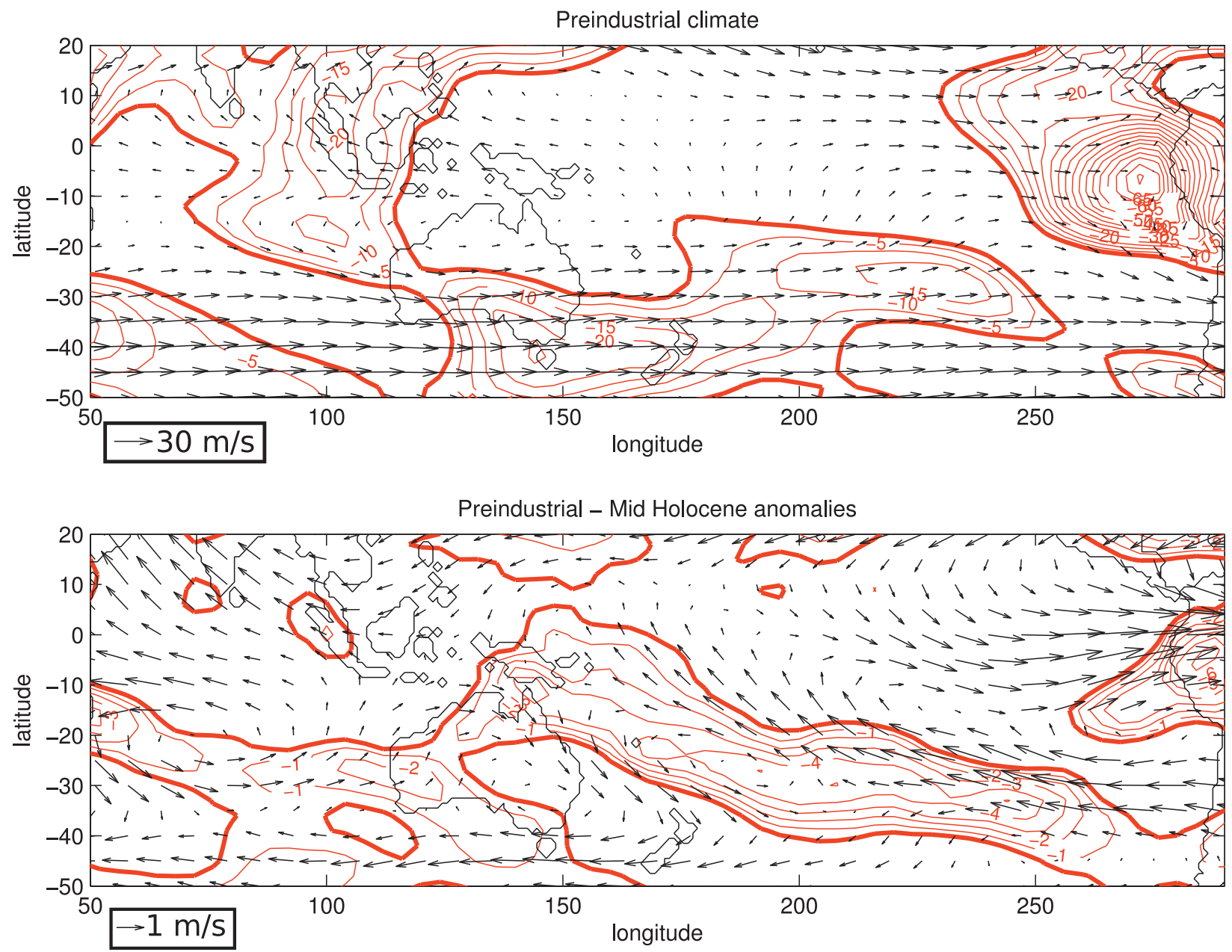

FIG. 5. Negative zonal stretching deformation (red lines) and horizontal wind vectors at $200 \mathrm{hPa}$ for the DJF season. (top) Climatological (preindustrial) conditions and (bottom) mid-Holocene minus preindustrial difference based on the PMIP2 ensemble mean. Contours are every $-5 \times 10^{-7} \mathrm{~s}^{-1}$ for the climatology and $-1 \times 10^{-7} \mathrm{~s}^{-1}$ for the differences. Thick red line represents the zero value in both panels.

analyzed, all underestimate the eastward tilt (or slope) of the SPCZ with latitude, with only the flux-adjusted MRI-CGCM2.3.4 approaching the observed slope (not shown).

In the current climate, precipitating deep convection in the subtropical part of the SPCZ is associated with an interaction between the background flow and eddies traveling east of Australia. To the east of Australia, the upper-level jet decelerates (Fig. 5) forming an area of negative zonal stretching deformation, that is, $\partial \bar{u} / \partial x<0$. The result is that eastward moving eddies slow down and their wavenumber decreases, but at the same time, wave energy density increases (Widlansky et al. 2011; Matthews 2012). Under mid-Holocene conditions, the zonal stretching deformation becomes more negative east of New Zealand around $30^{\circ} \mathrm{S}$. This means that the effect of the zonal stretching deformation on westward moving eddies and the associated precipitation increases, which is consistent with the subtropical part of the SPCZ shift.

Because tropical deep convection and SST tend to be strongly coupled, it is also important to consider how SST changes in the SPCZ region. Figure 6 shows the development of mid-Holocene minus preindustrial SST gradient parallel to the SPCZ, such that warming is associated with wetter conditions and cooling with drier conditions. Cai et al. 2012 document an analogous relationship between the variability of the SPCZ and the meridional SST gradient. More specifically, they suggest that in a warmer climate, the SPCZ is more likely to experience more pronounced meridional displacements with less precipitation on its southern edge and more precipitation in its core, as a result of reduced meridional SST gradient. The relationship between the SPCZ shift and the change in the SST gradient during the midHolocene will be further investigated in section 5 . 


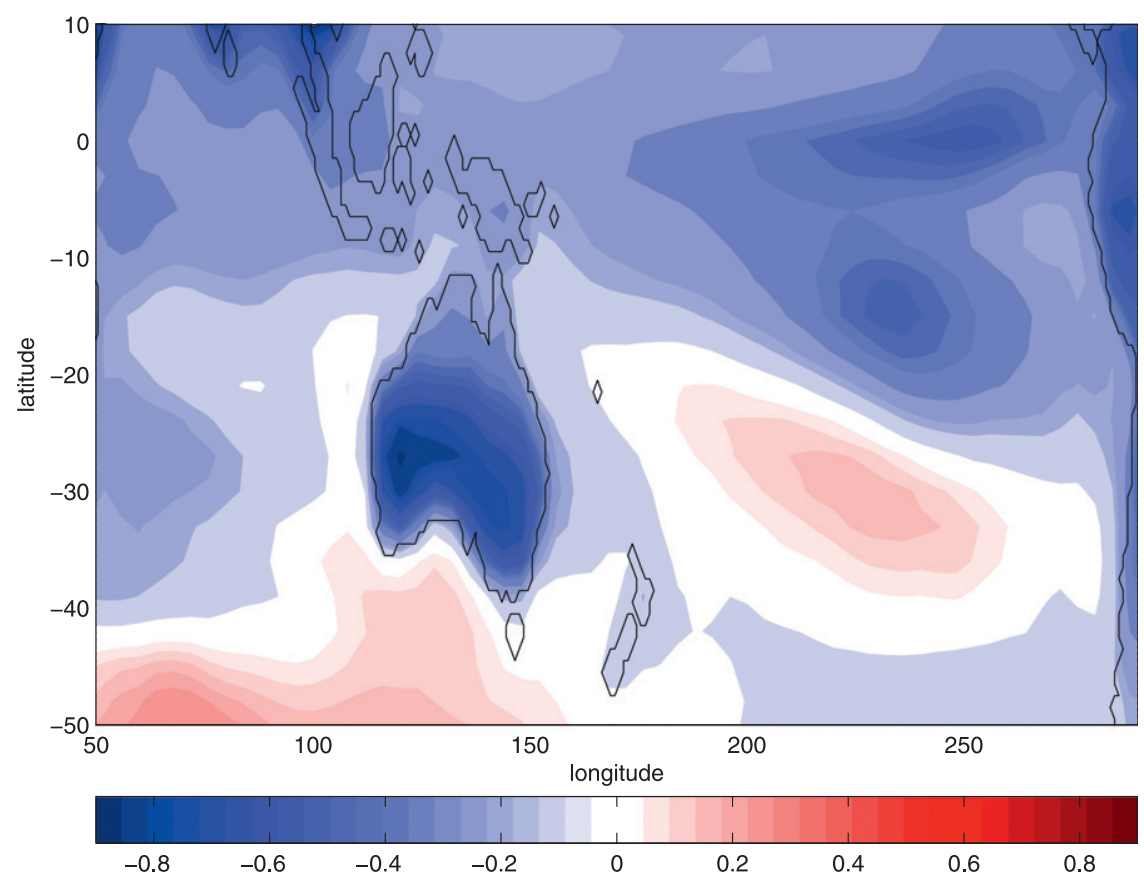

FIG. 6. PMIP2 ensemble mean mid-Holocene minus preindustrial DJF surface temperature change $\left({ }^{\circ} \mathrm{C}\right)$.

\section{Diagnostic moisture budget analysis}

To interpret the precipitation changes associated with the SPCZ shift, we first construct a diagnostic moisture budget. The moisture budget for climatological conditions, assuming monthly averages, can be expressed as

$\bar{P}=\bar{E}-\int_{P_{s}}^{0}\left(\overline{\mathbf{V}}_{H} \cdot \nabla_{H} \bar{q}\right) d p-\int_{P_{s}}^{0}\left(\bar{q} \nabla_{H} \cdot \overline{\mathbf{V}}_{H}\right) d p+$ Res.

Here overbars indicate monthly averages while the subscript $H$ indicates the horizontal components of the wind field and the divergence operator. The integrals on the rhs of Eq. (1) correspond to the vertical integrals of horizontal moisture advection and moisture convergence, respectively. To estimate the terms in Eq. (1) from the available PMIP2 output, spatial derivatives are discretized following the methodology in Seager et al. (2010). The residual term Res, estimated as the difference between monthly-mean precipitation and the sum of the first three terms on the rhs of Eq. (1), contains all covariances of submonthly variability, including transient eddies. Our estimates of the climatological moisture budget terms for preindustrial conditions (not shown) are comparable to the results of Seager et al. (2010), in which daily data were used to calculate the budget. This comparison indicates that the residual term in our study can be interpreted to leading order as the eddy contribution to the moisture budget:

$$
\operatorname{Res} \approx \int_{P_{s}}^{0}\left(\nabla \cdot \overline{q^{\prime} \mathbf{V}^{\prime}}\right) d p
$$

Moreover, calculation of the moisture budget directly from the daily data in the GFDL CM2.1, yields a very small residual compared to the other terms. This supports the interpretation of the residual from the monthly data calculations as the eddy contribution on submonthly time scales.

\section{a. Dynamic versus thermodynamic contribution to the moisture budget}

For the difference between mid-Holocene and preindustrial conditions, the change in the moisture budget, retaining only the dominant terms, can be expressed as

$$
\begin{aligned}
\delta P \approx & \delta E-\int_{P_{s}}^{0} \nabla_{H} \cdot\left[(\delta \bar{q}) \overline{\mathbf{V}}_{H}\right] d p \\
& -\int_{P_{s}}^{0} \nabla_{H} \cdot\left[\left(\delta \overline{\mathbf{V}}_{H}\right) \bar{q}\right] d p-\int_{P_{s}}^{0} \nabla \cdot \delta\left(\overline{q^{\prime} \mathbf{V}^{\prime}}\right) d p,
\end{aligned}
$$

where the notation $\delta$ indicates the difference (terms without $\delta$ denote preindustrial values). As in Seager et al. (2010), terms associated with changes in $q$ are viewed as 

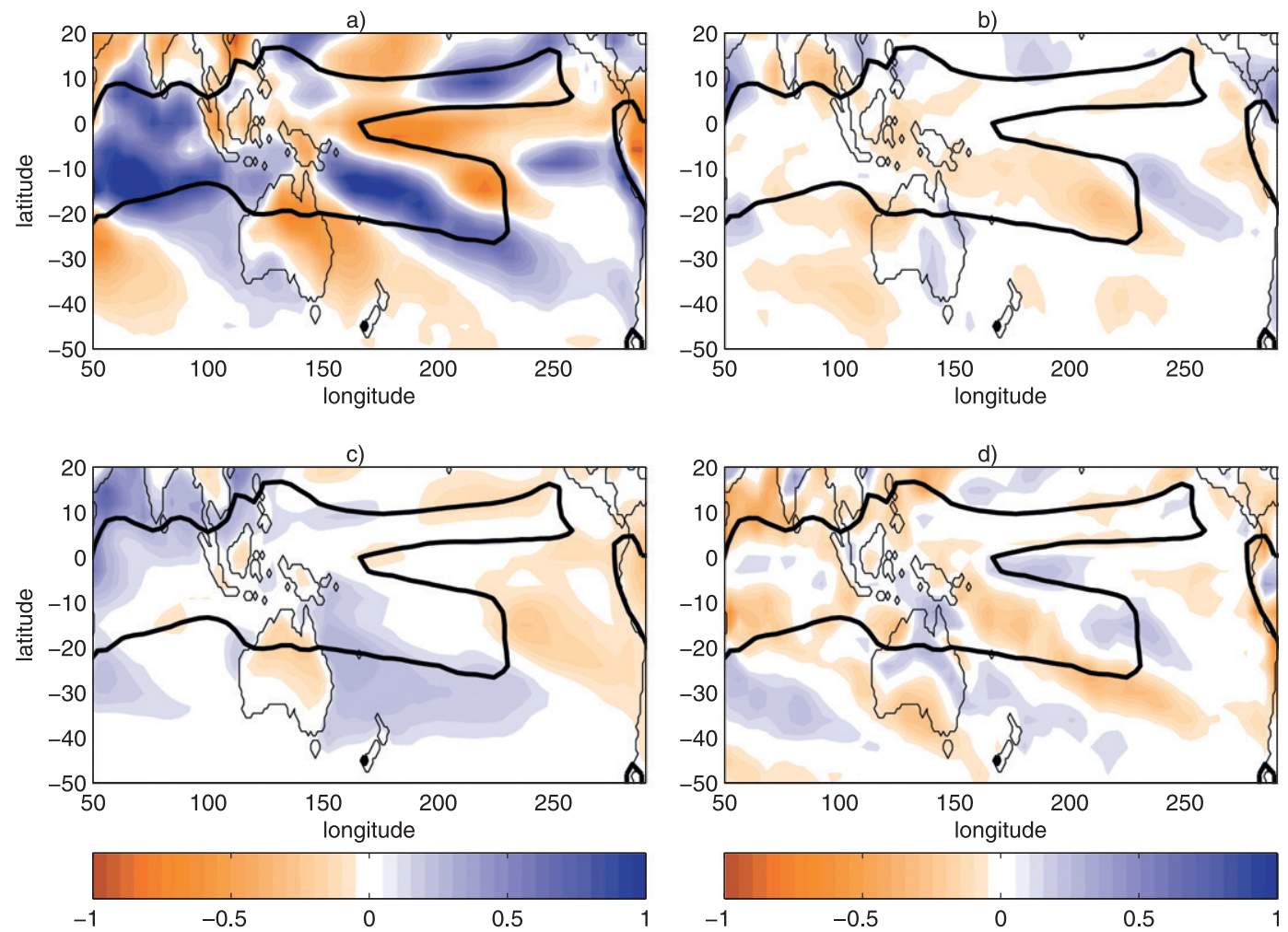

FIG. 7. DJF moisture budget analysis based on the PMIP2 model ensemble mean. The contribution to precipitation change ( $\mathrm{mm} \mathrm{day}^{-1}$; mid-Holocene minus preindustrial) from (a) mean dynamics, (b) mean thermodynamics, (c) evaporation, and (d) residual. Values $>1 \mathrm{~mm} \mathrm{day}^{-1}\left(<-1 \mathrm{~mm} \mathrm{day}^{-1}\right)$ have colors that have been saturated. The thick black line represents the $4 \mathrm{~mm}$ day $^{-1}$ contour of climatological precipitation (preindustrial) based on the PMIP2 ensemble mean.

thermodynamic contributors $(\delta \mathrm{TH})$ and terms associated with changes in $\mathbf{V}$ are viewed as dynamical contributors $(\delta \mathrm{DY})$ both associated with mean quantities:

$$
\begin{aligned}
& \delta \mathrm{TH}=-\int_{P_{s}}^{0} \nabla_{H} \cdot\left[(\delta \bar{q}) \overline{\mathbf{V}}_{H}\right] d p \quad \text { and } \\
& \delta \mathrm{DY}=-\int_{P_{s}}^{0} \nabla_{H} \cdot\left[\left(\delta \overline{\mathbf{V}}_{H}\right) \bar{q}\right] d p
\end{aligned}
$$

Figure 7a shows that the largest part of the precipitation change in the SPCZ region is associated with changes in the dynamical term of the mean circulation. (Note that all moisture budget terms presented in Figs. 7-9 are expressed in units of millimeters per day) However, these can be triggered by a change in the eddy activity. Under climatological conditions the eddy contribution to the moisture budget is of smaller magnitude compared to the mean convergence of moisture and is in fact negative (i.e., reducing precipitation) in the SPCZ region (cf. Fig. 1 of Seager et al. 2010); however, this does not mean that eddies do not play a role in triggering the occurrence of rainfall there. Indeed, through coupling between mean and eddy circulation, eddy activity can alter the mean circulation and organize convection in the SPCZ. Through this interaction, eddies can augment the convergence term that, to leading order, balances $P$. The fact that the eddy term appears to have a negative contribution to $P$ implies that the net effect of eddies, integrated over the vertical, is to transport moisture away from the SPCZ region toward higher latitudes. The appearance of a negative mid-Holocene minus preindustrial difference in the eddy term in the vicinity of the SPCZ shift (Fig. 7d) reflects an increasing impact of eddies on the zonal mean circulation during the mid-Holocene. That is, eddies strengthen convective activity and augment the dynamical term that balances the precipitation change in the SPCZ region. In contrast, the difference in the thermodynamic term (Fig. 7b) is negative throughout the SPCZ region, with this effect being stronger east of the SPCZ shift. Widlansky et al. (2013) found a similar contrasting relationship between changes in the dynamic and the thermodynamic terms, with the latter increasing and the former decreasing in the SPCZ region as a result of future warming. Finally, the evaporation increases in the region of the SPCZ shift, but decreases equatorward (Fig. 7c). 

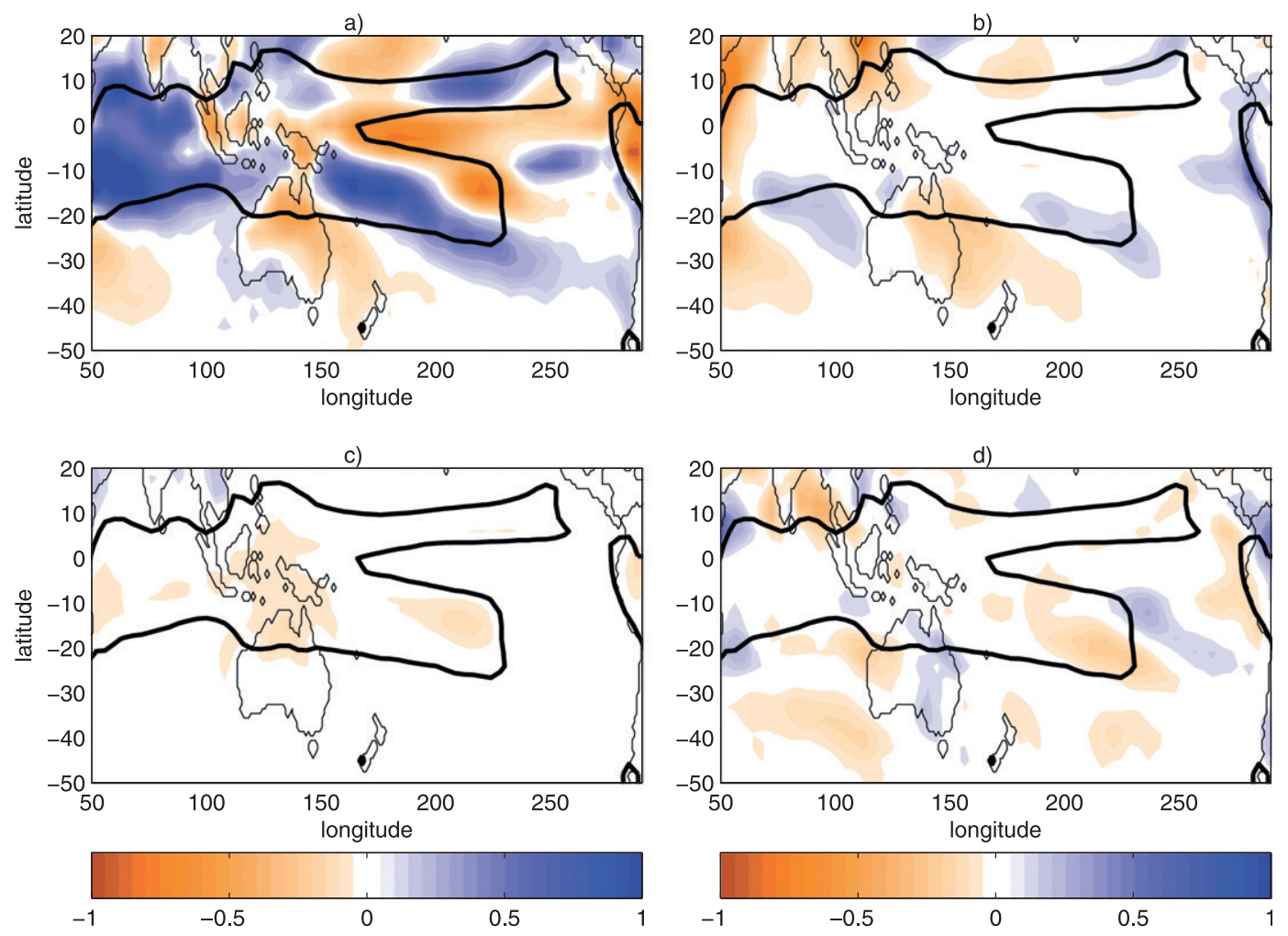

FIG. 8. As in Fig. 7, but for contributions from the (a) dynamic convergent term, (b) dynamic advection term,

(c) thermodynamic convergent term, and (d) thermodynamic advection term.

\section{b. Moisture advection versus moisture convergence}

To gain more understanding of the mechanisms controlling the SPCZ shift at mid-Holocene, we further separate the dynamic and thermodynamic effects into terms that reflect contribution from advection and convergence of moisture (Fig. 8) as in Seager et al. (2010):

$\delta \mathrm{TH}=-\int_{P_{s}}^{0}\left(\overline{\mathbf{V}}_{H} \cdot \nabla_{H} \delta \bar{q}\right) d p-\int_{P_{s}}^{0}\left(\delta \bar{q} \nabla_{H} \cdot \overline{\mathbf{V}}_{H}\right) d p \quad$ and

$\delta \mathrm{DY}=\int_{P_{s}}^{0}\left(\delta \overline{\mathbf{V}}_{H} \cdot \nabla_{H} \bar{q}\right) d p-\int_{P_{s}}^{0}\left(\bar{q} \nabla_{H} \cdot \delta \overline{\mathbf{V}}_{H}\right) d p$.

Such separation reveals that the moisture convergence via the change in circulation (i.e., the $\bar{q} \nabla \cdot \delta \overline{\mathbf{V}}$ term) balances precipitation to leading order (Fig. 8a). Of course, the collocation of large-scale deep convection and lowlevel convergence, especially in the tropics, is well known and by itself should not be viewed as indicating that the circulation change causes the precipitation change, that is, the moisture budget highlights how the different terms must balance in the transition between mid-Holocene and preindustrial conditions rather than the source or causality of these differences. Changes in the horizontal advection of moisture by the mean circulation add to the changes in moisture convergence, although the former are roughly an order of magnitude smaller than the latter (Fig. 8b). Finally, the thermodynamic terms exhibit small and mostly negative (drying) contributions to the overall moisture budget differences (Figs. 8c,d).

\section{c. Zonal, meridional, and vertical advection}

We further partition the moisture budget contributions of the mean and eddy circulations into zonal, meridional, and the vertical components (Fig. 9):

$$
\begin{aligned}
& M_{x}=-\delta\left\{\int_{P_{s}}^{0}\left[\frac{\bar{u}(\partial \bar{q})}{\partial x}\right] d p\right\} \text { and } \\
& E_{x}=-\delta\left\{\int_{P_{s}}^{0}\left[\frac{u^{\prime}\left(\partial q^{\prime}\right)}{\partial x}\right] d p\right\}, \\
& M_{y}=-\delta\left\{\int_{P_{s}}^{0}\left[\frac{\bar{v}(\partial \bar{q})}{\partial y}\right] d p\right\} \text { and } \\
& E_{y}=-\delta\left\{\int_{P_{s}}^{0}\left[\frac{v^{\prime}\left(\partial q^{\prime}\right)}{\partial y}\right] d p\right\},
\end{aligned}
$$



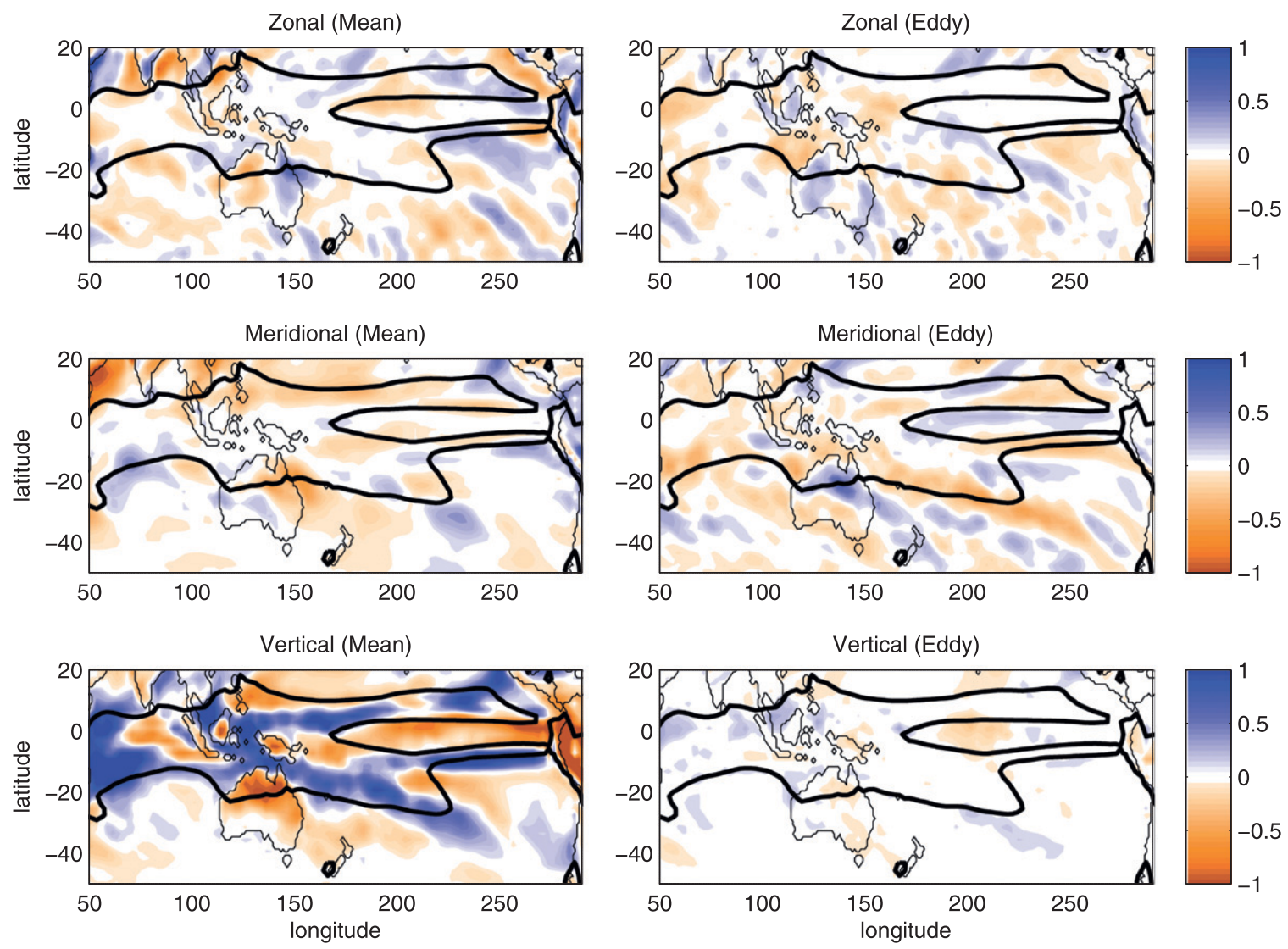

FIG. 9. Contribution to precipitation change $\left(\mathrm{mm} \mathrm{day}^{-1}\right.$; mid-Holocene minus preindustrial) from the change in mean zonal advection $\left(M_{x}\right)$, eddy zonal advection $\left(E_{x}\right)$, mean meridional advection $\left(M_{y}\right)$, eddy meridional advection $\left(E_{y}\right)$, mean vertical advection $\left(M_{z}\right)$, and eddy vertical advection $\left(E_{z}\right)$. Analysis was based on daily data from the GFDL CM2.1 model for the DJF season. Values $>1 \mathrm{~mm}$ day ${ }^{-1}$ $\left(<-1 \mathrm{~mm} \mathrm{day}^{-1}\right)$ have colors that have been saturated. The thick black line represents the $4 \mathrm{~mm} \mathrm{day}^{-1}$ contour of climatological precipitation (preindustrial) of the GFDL CM2.1 model.

and

$$
\begin{aligned}
& M_{z}=-\delta\left\{\int_{P_{s}}^{0}\left[\frac{\bar{\omega}(\partial \bar{q})}{\partial p}\right] d p\right\} \text { and } \\
& E_{z}=-\delta\left\{\int_{P_{s}}^{0}\left[\frac{\omega^{\prime}\left(\partial q^{\prime}\right)}{\partial P}\right] d p\right\} .
\end{aligned}
$$

Here the terms have not been explicitly separated into thermodynamic and dynamic. Also, for this partitioning we use only the daily data from GFDL CM2.1. Consistent with the results above, the change in the vertical advection by the mean circulation $\left(M_{z}\right)$ is the dominant term (Fig. 9). Among the horizontal mean circulation terms, the mean meridional term $\left(M_{y}\right)$ has a weakly positive association with the SPCZ shift, while the zonal term $\left(M_{x}\right)$ is much noisier and has a negative contribution to the moisture budget at higher latitudes. In contrast to the mean circulation terms, the eddy terms produce an overall negative contribution, with the meridional component $\left(E_{y}\right)$ clearly dominating. The sign of this term is consistent with an increase in the net poleward eddy flux of moisture: for preindustrial conditions, this term is negative along the SPCZ, and it becomes more negative during the mid-Holocene. The vertical component $\left(E_{z}\right)$ is mostly positive but relatively small. Finally, the zonal component $\left(E_{x}\right)$ differences tend to be negative in the SPCZ region, although these are rather spatially heterogeneous.

\section{Simulations with QTCM}

Despite its relative simplicity, QTCM is found to simulate a zone of deep convection east of Australia resembling the SPCZ (Figs. 10, 11). Of course, the QTCM-simulated SPCZ lacks the proper longitudinal slope, as most GCMs do (Brown et al. 2011, 2013). Another limitation of QTCM is its simulation of a very weak Pacific ITCZ, especially in the eastern part of the basin. 

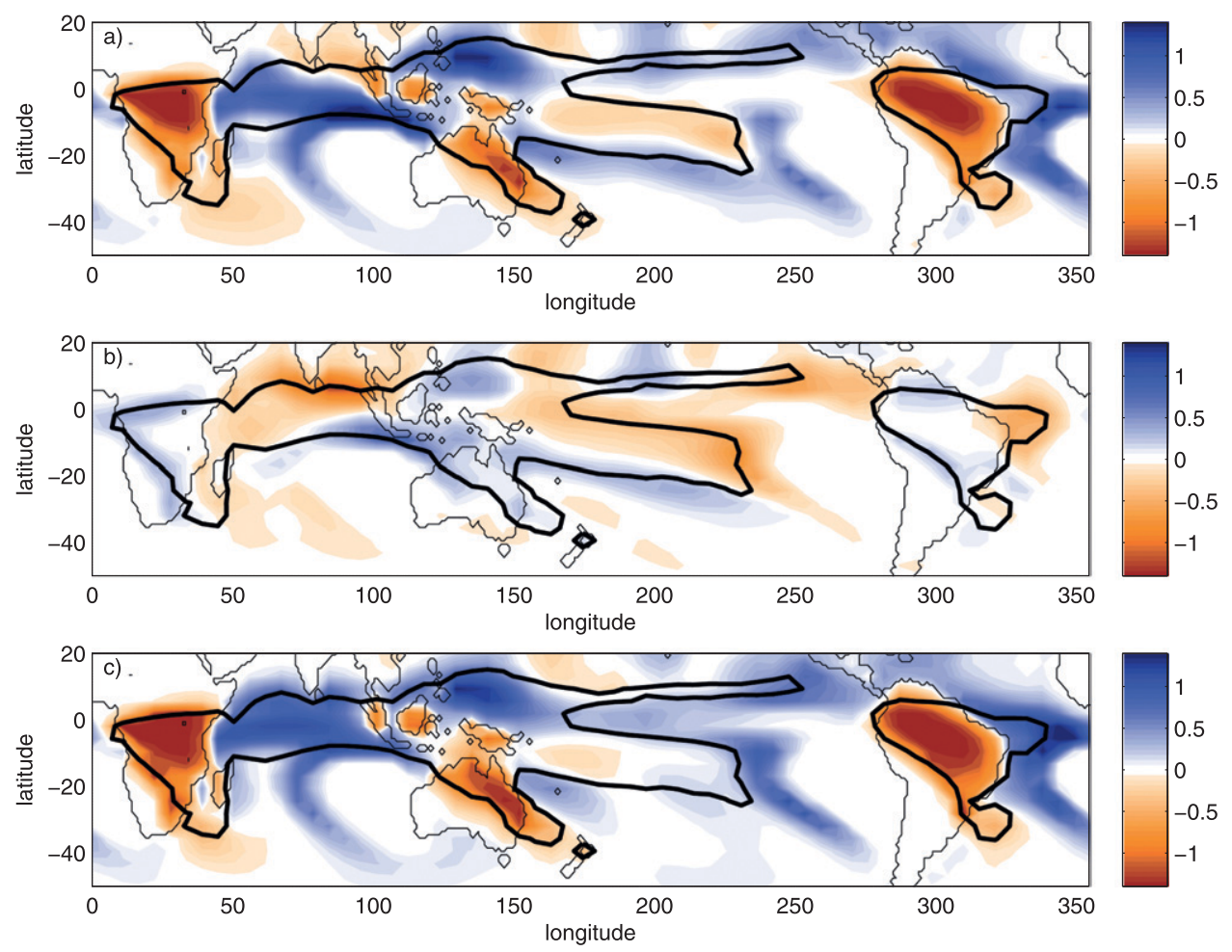

FIG. 10. DJF precipitation anomalies $\left(\mathrm{mm} \mathrm{day}^{-1}\right)$ from the atmospheric version of QTCM: (a) response to a change in both SSTs and TOA insolation, (b) response to a change in the SSTs alone (keeping the TOA insolation fixed), and (c) response to a change in TOA insolation alone (keeping the SSTs fixed). SSTs were taken from the PMIP2 ensemble mean. Values $>1.4 \mathrm{~mm} \mathrm{day}^{-1}\left(<-1.4 \mathrm{~mm} \mathrm{day}^{-1}\right)$ have colors that have been saturated. The thick black line represents the $4 \mathrm{~mm}^{-1}{ }^{-1}$ contour of climatological precipitation (CTRL $L_{S S T}$ experiment).

We now explore SPCZ region precipitation changes during the mid-Holocene as simulated by QTCM. Before doing so we consider the extent to which QTCM replicates the precipitation changes simulated by the PMIP2 models. For this, we perform two runs, denoted CTRL $\mathrm{SST}_{\mathrm{SS}}$ and $\mathrm{MH}_{\mathrm{SST}}$, in which preindustrial and mid-Holocene TOA insolation and SSTs are applied, respectively (see Table 2). In each run, the SST forcing comprises the PMIP2 ensemble mean. (Of course, because QTCM is forced with PMIP2 model-generated SSTs, any coupled simulation SST bias could impact the results; we do not directly address such biases here.) Comparing the two runs reveals that QTCM captures many of the principal features of mid-Holocene minus preindustrial DJF precipitation change seen in the PMIP2 ensemble (Fig. 10a). Most importantly for the present study, the QTCM simulations manifest an elongated precipitation dipole along the SPCZ, with DJF precipitation enhanced to the south and west in the mid-Holocene, albeit with changes of smaller amplitude relative to the PMIP2 ensemble mean. The SH summertime continental convection is also weakened, although in this case, QTCM overestimates the weakening relative to the PMIP2 ensemble mean. Such differences can be broadly understood in terms of some known mean climate biases in this version of QTCM, namely, too intense precipitation over tropical continents and somewhat too weak precipitation over the oceans. On the other hand, QTCM fails to simulate the drying in the equatorial Pacific seen in the PMIP2 models.

To assess the processes controlling the shift in the SPCZ, we consider a simple linear decomposition of the forcing. We speculate that at least two major processes may contribute to the shift in the SPCZ at the midHolocene. First, the SPCZ shift could be coupled to the underlying SST gradient, through the Lindzen-Nigam mechanism (Lindzen and Nigam 1987), in which an anomalous SST gradient alters low-level convergence that in turn modulates convection. Second, the weakening of the continental monsoons may influence the SPCZ. Kiladis et al. (1989) have argued that the absence of the Australian monsoon would eliminate the continental heating and the monsoonal circulation as well as the associated low-level convergence that generates precipitation in the SPCZ. 

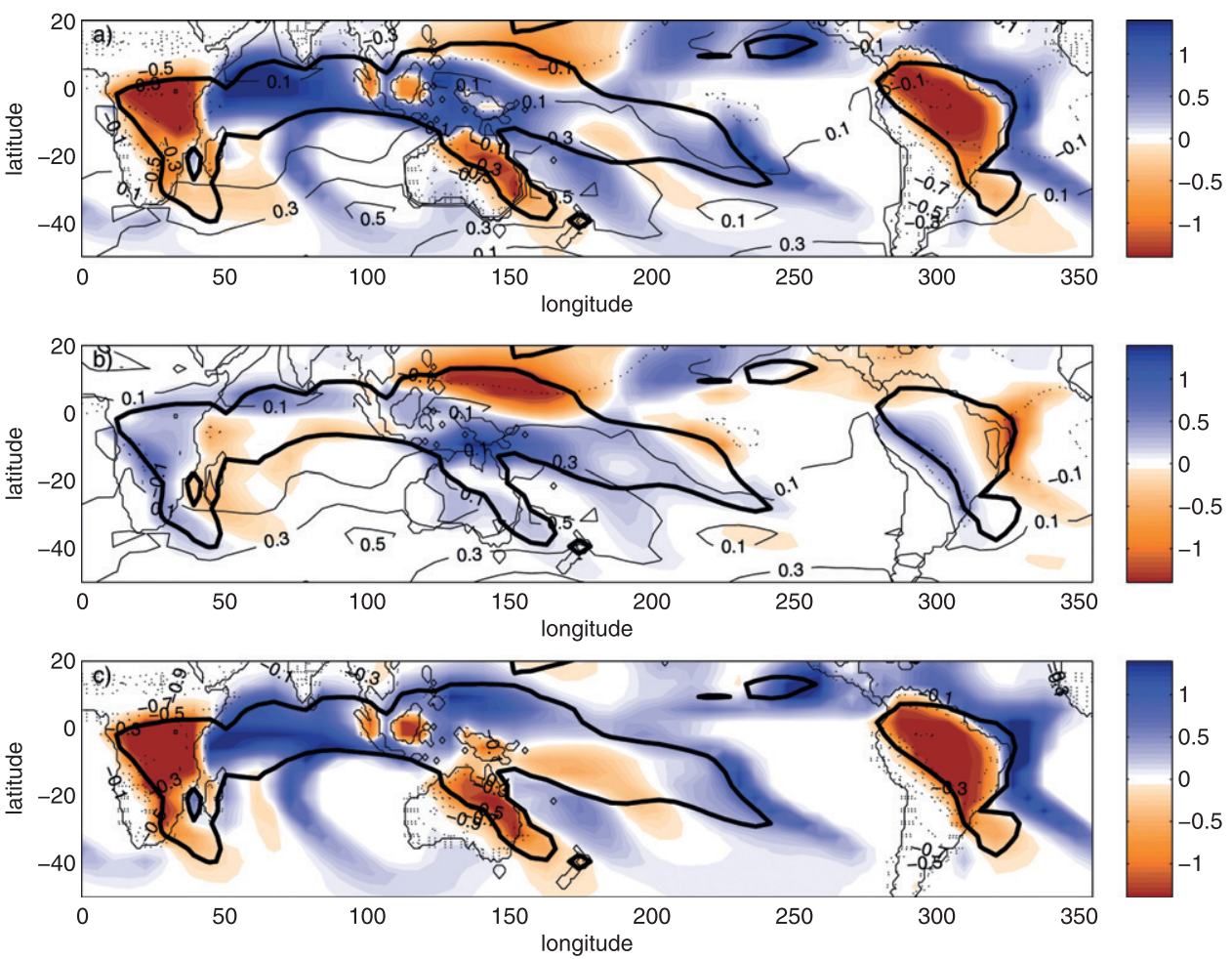

FIG. 11. As in Fig. 10, but with SSTs taken from the QTCM slab ocean runs corresponding to the midHolocene and preindustrial period. The thin black lines represent changes in surface temperature $\left({ }^{\circ} \mathrm{C}\right)$ with positive (negative) changes represented by solid lines (dashed lines).

Therefore, we perform an additional set of two QTCM experiments (Table 2): in the first, denoted $\mathrm{SST}_{6 \mathrm{k}}$, a combination of mid-Holocene SSTs and preindustrial TOA insolation is prescribed, while in the second, denoted $\mathrm{TOA}_{6 \mathrm{k}}$, mid-Holocene TOA insolation and preindustrial SSTs are applied. Thus, the comparison of CTRL $\mathrm{SST}_{\mathrm{ST}}$ and $\mathrm{SST}_{6 \mathrm{k}}$ isolates the effect of changing SSTs while keeping TOA insolation fixed (Fig. 10b). On the other hand, comparison of CTRL $\mathrm{SST}_{\mathrm{SS}}$ and $\mathrm{TOA}_{6 \mathrm{k}}$ isolates the effect of the change in TOA insolation with SSTs fixed (Fig. 10c). Comparing these experiments suggests that the change in SSTs, and more specifically the SST gradient, largely controls the SPCZ shift from $10^{\circ}$ to $30^{\circ} \mathrm{S}$, with a maximum impact around $20^{\circ} \mathrm{S}$. Also worth noting is that the SST change is responsible for the drying along the equator as well as the subtropical central South Pacific, although this is absent in the full experiment (Fig. 10a). On the other hand, the change in SSTs has little effect on the continental monsoons, which are affected by the reduction in the TOA insolation only (Fig. 10c). Our experiments also demonstrate that the TOA forcing has an indirect impact on the SPCZ (Fig. 10c), which is more localized to the tropics and consists of an increase of precipitation to the east of Australia and a slight reduction to the northeast of this. Studies based on current climate conditions (e.g., Kiladis et al. 1989; Vincent 1994) suggest that diabatic monsoonal heating over Australia in particular plays a major role for the development of the more zonal, tropical portion of the SPCZ, especially during DJF when continental heating is maximized.

Forcing QTCM with preindustrial SSTs and TOA insolation everywhere except Australia, where midHolocene insolation is prescribed, results in localized weakening of the Australian monsoon alone, with other

TABLE 2. Details regarding the TOA forcing and the lower boundary conditions over the oceans for the experiments performed with QTCM; $\mathrm{ka}=1000$ years.

\begin{tabular}{|c|c|c|}
\hline Experiment & Insolation (ka) & SSTs \\
\hline $\mathrm{CTRL}_{\mathrm{SST}}$ & 0 & $\begin{array}{l}\text { Prescribed (PMIP2 0-ka } \\
\text { ensemble mean) }\end{array}$ \\
\hline $\mathrm{MH}_{\mathrm{SST}}$ & 6 & $\begin{array}{l}\text { Prescribed (PMIP2 6-ka } \\
\text { ensemble mean) }\end{array}$ \\
\hline $\mathrm{SST}_{6 \mathrm{k}}$ & 0 & $\begin{array}{l}\text { Prescribed (PMIP2 6-ka } \\
\text { ensemble mean) }\end{array}$ \\
\hline $\mathrm{TOA}_{6 \mathrm{k}}$ & 6 & $\begin{array}{l}\text { Prescribed (PMIP2 0-ka } \\
\text { ensemble mean) }\end{array}$ \\
\hline $\mathrm{CTRL}_{\mathrm{SLAB}}$ & 0 & Interactive slab ocean \\
\hline $\mathrm{MH}_{\text {SLAB }}$ & 6 & Interactive slab ocean \\
\hline $\mathrm{SST}_{6 \mathrm{k}-\mathrm{QTCM}}$ & 0 & Prescribed $\left(\mathrm{MH}_{\mathrm{SLAB}}\right)$ \\
\hline TOA $_{6 \mathrm{k}-\mathrm{QTCM}}$ & 6 & Prescribed (CTRL $\left.{ }_{S L A B}\right)$ \\
\hline
\end{tabular}


continents relatively unaffected (not shown). This is accompanied by a shift of the tropical part of the SPCZ to the southwest, similar to that shown in Fig. 10c, implying that the SPCZ shift is remotely influenced by the weakening of the Australian monsoon and not by the other monsoonal systems (South America or Africa). In a similar experiment, it was shown that the precipitation increase in the subtropical central South Pacific, on the eastern edge of the SPCZ (seen in Fig. 10c), was attributed to the weakening of the South American monsoon (results of this experiments are not shown). However, some caution is warranted in assessing the significance of the Australian or the South American monsoon impacts since QTCM tends to overestimate the strength of the preindustrial SH continental monsoons as well as their degree of weakening in the mid-Holocene. For example, in QTCM the maximum weakening of the Australian monsoon is roughly $-1.6 \mathrm{~mm} \mathrm{day}^{-1}$ (Fig. 10a) compared to $-0.7 \mathrm{~mm} \mathrm{day}^{-1}$ in the PMIP2 ensemble mean (Fig. 3). This suggests that the remote effect of the weakening of the Australian monsoon on the SPCZ is likely overestimated in QTCM. The overestimation of the weakening of the monsoons as well as their remote effect on the precipitation over the ocean is also the reason why QTCM fails to simulate the drying along the equator in the Pacific seen in the PMIP2 models. Another interesting aspect of these experiments is that the summed precipitation anomalies from changing SSTs and TOA insolation separately are nearly equal to the precipitation anomalies to the full experiment: this near equality implies that the separation of the precipitation anomalies into SST- and TOA-forced components is effectively linear.

The above results indicate coupling of the midHolocene minus preindustrial differences in SPCZ precipitation to SSTs. According to Hsu et al. (2010), midHolocene SST change represents the lagged response to orbital forcing and is attributed to the large ocean thermal inertia. Broccoli (2000) highlighted the potential role of temperature advection for regional tropical SST change during the LGM, and a similar effect could be present during the mid-Holocene. Here we perform a set of slab ocean experiments analogous to Hsu et al. (2010) (Table 2). While the difference between these two runs (denoted CTRL $_{\text {SLAB }}$ and $\mathrm{MH}_{\mathrm{SLAB}}$ ) yields an SPCZ shift (Fig. 11a), the axis of these differences is much steeper and is located farther to the south compared to the PMIP2 models or QTCM forced with PMIP2 ensemble-mean SSTs. On the other hand, the slab version of QTCM appears to underestimate the Pacific ITCZ, although the effect this might have on mid-Holocene-induced SPCZ variability is not addressed in this study.

Again we examine the individual influences of insolation and SST by forcing QTCM with the SSTs produced by the slab ocean version. The response of precipitation to the insolation change (experiment TOA $_{6 \mathrm{k}-\mathrm{QTCM}}$; Fig. 11b) is qualitatively similar to the results using PMIP2 SSTs, with SH continental monsoons weakening, and the SPCZ experiencing a shift that is remotely forced. It should be noted though that the anomalies associated with the SPCZ are greater and extend into the subtropics in this case. On the other hand, the effect of changing SSTs is significantly different (experiment $\mathrm{SST}_{6 \mathrm{k}-\mathrm{QTCM}} ; \mathrm{Fig} .11 \mathrm{c}$ ), with a general increase in precipitation in the SPCZ region, and no SPCZ shift, even though precipitation increases in the southern edge of the SPCZ. The most likely reason is the fact that the west Pacific SST change simulated by the slab ocean version (Fig. 11) does not resemble the warm-cold dipole seen in the PMIP2 models (Fig. 6). Overall, we suggest that the effect of mixed layer thermal adjustment in QTCM is by itself insufficient to generate the SPCZ region SST change evident in the PMIP2 models with fully dynamical oceans, indicating a potentially important role for ocean dynamics in the SPCZ shift. Another possible explanation could be that QTCM SSTs do not exhibit the same sensitivity to the windevaporation-SST (WES) feedback as in full GCMs. The WES feedback has been hypothesized as a possible source of SST and precipitation change in the South Pacific (Xie et al. 2010).

An experiment changing insolation only over Australia was also performed with the slab ocean QTCM in order to test whether weakening of the Australian monsoon could account for the anomalous SST gradient. In this case, the induced SST gradient could act as (positive) feedback, driving additional anomalous low-level convergence and further enhancing the SPCZ shift. Although QTCM does not support the operation of such a mechanism (not shown), performing such an experiment using a model with a dynamical ocean would clearly be of interest.

\section{Summary and discussion}

Simulated mid-Holocene tropical precipitation differed substantially from preindustrial conditions. Among such differences are the weakening of local summertime precipitation over the Southern Hemisphere continents and widespread increases of precipitation over tropical oceans, with the exception of the equatorial Pacific where drying occurs. The SPCZ, the focus of the present study, appears to have shifted to the south and west along its entire extent from the tropics to midlatitudes during the mid-Holocene. Analysis of a diagnostic moisture budget reveals a complex interplay of processes associated with the SPCZ shift. The enhanced mid-Holocene convection to the south and west is balanced to leading order by 
increased moisture convergence by the mean atmospheric flow, which is partly attributed to a change in the eddy activity. We note, for example, that simulated changes in upper-level negative zonal stretching deformation along the southwestern edge of the SPCZ are consistent with enhanced mid-Holocene precipitation to the southwest in accordance with the "eddy graveyard" theory (Trenberth 1976; Widlansky et al. 2011).

Our results also indicate a relationship between the SPCZ shift and changes in the underlying spatial distribution of SST: the PMIP2 models simulate an anomalous SST dipole with warmer $6 \mathrm{kyr}$ BP SSTs to the southwest and cooler SSTs to the northeast. Idealized experiments with QTCM, an intermediate-level complexity model forced with PMIP2 model-generated SSTs, indicate that the SPCZ shift in the tropics and the extratropics, as well as the drying in the equatorial and the tropical central South Pacific, are dominated by the changes in the underlying SSTs. The tropical portion of the SPCZ shift is further impacted, though to a lesser extent, by the weakening of the Australian monsoon, which is forced by changes in TOA insolation with little influence from the lagged SST response to prior seasonal insolation. The weakening of the Australian monsoon exerts a remote impact on the tropical portion of the SPCZ but leaves the SPCZ unaffected at higher latitudes. The South American and African monsoons also respond to changing TOA insolation but have little effect on the SPCZ shift.

The QTCM slab ocean experiments indicate that coupling of an atmosphere to a constant depth slab ocean cannot generate the change in the SSTs that would support a southwestward shift in the SPCZ as documented by the PMIP2 models. Of course, it is wellknown that the depth of the mixed layer varies substantially across the Pacific basin, with a much deeper thermocline in the west, so it is possible that the use of more realistic mixed layer depths could alter the results. Apart from interactive ocean dynamics, the fact that QTCM is an intermediate-level complexity model may mean that not all of the relevant physics are represented. However, a study by Clement et al. (2004) with a more complex GCM coupled to a slab ocean showed that a change in precession by $180^{\circ}$ (in the $\mathrm{SH}$, such forcing is accompanied by reduced DJF insolation and is thus qualitatively similar to the mid-Holocene forcing) simulates a weakening of SH monsoons but not an SPCZ shift; rather, their results show strengthening of the SPCZ. This indicates that the lack of ocean dynamics is the most probable cause for the inaccurate representation of the SST change.

Any study based on GCMs is subject to some biases and, consequently, limitations, although use of ensemble means may help to mitigate the impacts of such biases. A common bias evident in the PMIP2 ensemble mean is the underestimation of the westward tilt of the SPCZ with longitude, which is partly the result of biases in the underlying SSTs. Forcing the atmospheric version of QTCM with PMIP2 model-generated SSTs that contain such a bias is going to have a similar effect on the slope of the simulated SPCZ by QTCM. Another bias present in QTCM that could affect the interpretation of our results is the overly strong Australian monsoon: the occurrence of a too strong monsoon may amplify the response to the insolation forcing as well as its remote effect on the SPCZ. Furthermore, the strength of the East Pacific ITCZ is also underestimated, which could affect the simulation of the SPCZ and its variability.

The weakening of the Southern Hemisphere monsoons seen in this study is consistent with the work of Kutzbach and Otto-Bliesner (1982), who were able to simulate the enhanced intensity of the Northern Hemisphere monsoons during the mid-Holocene by changing only the insolation and leaving the SSTs fixed to preindustrial values. More recent studies, however, showed that ocean feedbacks play a more complicated role that varies across models as well as monsoonal regions. Zhao and Harrison (2012) show that ocean feedbacks generally amplify the orbital induced strengthening of the Northern Hemisphere monsoons during the mid-Holocene. The same study also shows that ocean feedbacks weaken the response of the Southern Hemisphere monsoons to orbital forcing, such that the decrease in rainfall is smaller than might otherwise be expected. According to Liu et al. (2004), this feedback is particularly strong for the Australian monsoon and may have resulted in an intensified mid-Holocene monsoon. However, it should be noted that Liu et al. (2004) used only one model (FOAM), and other models from the PMIP2 archive in fact show that the Australian monsoon weakens during the mid-Holocene (Zhao and Harrison 2012).

It is also of interest to consider how the mid-Holocene SPCZ shift compares to what the SPCZ experiences under twenty-first-century global warming. Studies of the latter, show an increase in rainfall along the equator and a broader reduction elsewhere (Xie et al. 2010; Ma et al. 2012; Brown et al. 2012; Widlansky et al. 2013). However, in this case we see a widespread warming throughout the tropical Pacific, with precipitation increasing where the warming is maximum and decreasing where the warming is a minimum.

We note that the SPCZ experiences spatial displacements during ENSO events. For example, for La Niña conditions, the daily probability of a westward-shifted SPCZ event may increase by a factor of 2 (Folland et al. 2002; Matthews 2012). For the La Niña case, the SPCZ 
shift is associated with a basin-wide warm-cold zonal SST dipole, similar to what we see in the mid-Holocene. Precisely how the mechanisms of spatial displacements on different time scales relate to one another remains unclear.

Finally, the fact that the SPCZ lies mostly over the ocean has limited the availability of precipitation proxies. The paucity of high-resolution precipitation proxies in the SPCZ region precludes through evaluation of the simulated mid-Holocene SPCZ variability seen in models. However, proxies from islands located in the SPCZ region would clearly be beneficial for examining how the SPCZ changed in the past. Thus, we hope that the analysis presented here will stimulate the collection of such proxies.

Acknowledgments. We thank Chia Chou, Matthew Widlansky, and Adrian Matthews for useful discussions; Michael P. Erb for providing the daily data from the GFDL CM2.1 model; and Matthew J. Niznik for graphical assistance. This work was supported by $\mathrm{Na}$ tional Science Foundation (NSF) Paleoclimate Perspectives on Climate Change Initiative Grant AGS-1103209. We acknowledge the international modeling groups for providing their data for analysis and the Laboratoire des Sciences du Climat et de l'Environnement (LSCE) for collecting and archiving the model data. The PMIP2 Data Archive is supported by CEA, CNRS, and the Programme National d'Étude de la Dynamique du Climat (PNEDC). The PMIP2 data analyzed are version 10-01-2011.

\section{REFERENCES}

Baker, P. A., and Coauthors, 2001: Tropical climate change at millennial and orbital timescales on the Bolivian Altiplano. Nature, 409, 698-700.

Braconnot, P., and Coauthors, 2007: Results of PMIP2 coupled simulations of the mid-Holocene and Last Glacial MaximumPart 1: Experiments and large-scale features. Climate Past, 3, 261-277.

Broccoli, A. J., 2000: Tropical cooling at the Last Glacial Maximum: An atmosphere-mixed layer ocean model simulation. J. Climate, 13, 951-976.

Brown, J. R., S. B. Power, F. P. Delage, R. A. Colman, A. F. Moise, and B. F. Murphy, 2011: Evaluation of the South Pacific convergence zone in the IPCC AR4 climate model simulations of the twentieth century. J. Climate, 24, 1565-1582.

_ A. F. Moise, and F. P. Delage, 2012: Changes in the South Pacific convergence zone in IPCC AR4 future climate projections. Climate Dyn., 39, 1-19.

,$- \ldots$, and R. A. Colman, 2013: The South Pacific convergence zone in CMIP5 simulations of historical and future climate. Climate Dyn., doi:10.1007/s00382-012-1591-x, in press.

Cai, W., A. Sullivan, and T. Cowan, 2009: Rainfall teleconnections with Indo-Pacific variability in the WCRP CMIP3 models. J. Climate, 22, 5046-5071.

, and Coauthors, 2012: More extreme swings of the South Pacific convergence zone due to greenhouse warming. Nature, 488, 365-370.
Carre, M., and Coauthors, 2012: Mid-Holocene mean climate in the south eastern Pacific and its influence on South America. Quat. Int., 253, 55-66.

Clement, A. C., A. Hall, and A. J. Broccoli, 2004: The importance of precessional signals in the tropical climate. Climate Dyn., 22, 327-341.

Cruz, F. W., and Coauthors, 2005: Insolation-driven changes in atmospheric circulation over the past 116,000 years in subtropical Brazil. Nature, 434, 63-66.

Dai, A., 2006: Precipitation characteristics in eighteen coupled climate models. J. Climate, 19, 4605-4630.

Delcroix, T., S. Cravatte, and M. J. McPhaden, 2007: Reconstructing twentieth-century sea surface temperature variability in the southwest Pacific: A replication study using multiple coral $\mathrm{Sr} / \mathrm{Ca}$ records from New Caledonia. Paleoceanography, 22, PA4212, doi:10.1029/2007PA001444.

Delworth, T. L., and Coauthors, 2006: GFDL's CM2 global coupled climate models. Part I: Formulation and simulation characteristics. J. Climate, 19, 643-674.

Folland, C. K., J. A. Renwick, M. J. Salinger, and A. B. Mullan, 2002: Relative influences of the interdecadal Pacific oscillation and ENSO on the South Pacific convergence zone. Geophys. Res. Lett., 29 (13), doi:10.1029/2001GL014201.

Gomez, B., L. Carter, N. A. Trustrum, A. S. Palmer, and A. P. Roberts, 2004: El Niño-Southern Oscillation signal associated with middle Holocene climate change in intercorrelated terrestrial and marine sediment cores, North Island, New Zealand. Geology, 32, 653-656.

Haberle, S. G., 1998: Late Quaternary vegetation changes in the Tari basin Papua New Guinea. Palaeogeogr. Palaeoclimatol. Palaeoecol., 137, 1-24.

Haibin, W., J. Guiot, S. Brewer, and Z. Guo, 2007: Climatic changes in Eurasia and Africa at the last glacial maximum and mid-Holocene: Reconstruction from pollen data using inverse vegetation modeling. Climate Dyn., 29, 211-229.

Hsu, Y.-H., C. Chou, and K.-Y. Wei, 2010: Land-ocean asymmetry of tropical precipitation changes in the mid-Holocene. J. Climate, 23, 4133-4151.

Jomelli, V., and Coauthors, 2011: Irregular tropical glacier retreat over the Holocene epoch driven by progressive warming. Nature, 474, 196-199.

Jully, D., and Coauthors, 1998: Biome reconstruction from pollen and plant macrofossil data for Africa and the Arabian peninsula at 0 and 6 ka. J. Biogeogr., 25, 10071027.

Kiladis, G. N., H. von Storch, and H. von Loon, 1989: Origin of the South Pacific convergence zone. J. Climate, 2, 11851195.

Kodama, Y.-M., 1992: Large-scale common features of subtropical precipitation zones (the baiu frontal zone, the SPCZ, and the SACZ. Part I: Characteristics of subtropical frontal zones. J. Meteor. Soc. Japan, 70, 831-835.

_ 1993: Large-scale common features of subtropical precipitation zones (the baiu frontal zone, the SPCZ, and the SACZ). Part II: Conditions of the circulations for generating the STCZ. J. Meteor. Soc. Japan, 71, 581-610.

_ 1999: Roles of the atmospheric heat sources in maintaining the subtropical convergence zones: An aqua-planet GCM study. J. Atmos. Sci., 56, 4032-4049.

Kutzbach, J. E., and B. L. Otto-Bliesner, 1982: The sensitivity of the African-Asian monsoonal climate to orbital parameter changes for 9000 years B.P. in a low-resolution general circulation model. J. Atmos. Sci., 39, 1177-1188. 
Lin, J.-L., 2007: The double-ITCZ problem in IPCC AR4 coupled GCMs: Ocean-atmosphere feedback analysis. J. Climate, 20, 4497-4525.

Lindzen, R. S., and S. Nigam, 1987: On the role of sea surface temperature gradient in forcing low-level winds and convergence in the tropics. J. Atmos. Sci., 44, 2418-2436.

Linsley, B. K., P. Zhang, A. Kaplan, S. S. Howe, and G. M. Wellington, 2008: Interdecadal-decadal climate variability from multicoral oxygen isotope records in the South Pacific convergence zone region since 1650 A.D. Paleoceanography, 23, PA2219, doi:10.1029/2007PA001539.

Lintner, B. R., and J. D. Neelin, 2008: Eastern margin variability of the South Pacific convergence zone. Geophys. Res. Lett., 35, L16701, doi:10.1029/2008GL034298.

Liu, Z., S. P. Harrison, J. Kutzbach, and B. Otto-Bliesner, 2004: Global monsoons in the mid-Holocene and oceanic feedback. Climate Dyn., 22, 157-182.

Ma, J., S.-P. Xie, and Y. Kosaka, 2012: Mechanisms for tropical tropospheric circulation change in response to global warming. J. Climate, 25, 2979-2994.

Marshall, A. G., and A. H. Lynch, 2006: Time-slice analysis of the Australian summer monsoon during the late Quaternary using the Fast Ocean Atmosphere Model. J. Quat. Sci., 21, 789-801.

Matthews, A. J., 2012: A multiscale framework for the origin and variability of the South Pacific convergence zone. Quart. J. Roy. Meteor. Soc., 138, 1165-1178.

- and H. Y. Li, 2005: Modulation of station rainfall over the western Pacific by the Madden-Julian oscillation. Geophys. Res. Lett., 32, L14827, doi:10.1029/2005GL023595.

Neelin, J. D., and N. Zeng, 2000: A quasi-equilibrium tropical circulation model-Formulation. J. Atmos. Sci., 57, 17411766.

Partridge, C. T., P. B. DeMenocal, S. A. Lorentz, M. J. Paiker, and J. C. Vogel, 1997: Orbital forcing of climate over South Africa: A 200,000-year rainfall record from the Pretoria saltpan. Quat. Sci. Rev., 16, 1125-1133.

Peterson, L. C., and G. H. Haug, 2006: Variability in the mean latitude of the Atlantic intertropical convergence zone as recorded by riverine input of sediments to the Cariaco Basin. Palaeogeogr. Palaeoclimatol. Palaeoecol., 234, 97-113.

Reynolds, R. W., and T. M. Smith, 1994: Improved global sea surface temperature analysis using optimum interpolation. J. Climate, 7, 929-948.

Saez, A., and Coauthors, 2009: Glacial to Holocene climate changes in the SE Pacific. The Raraku Lake sedimentary record (Easter Island, 27 S). Quat. Sci. Rev., 28, 2743-2759.
Salinger, M. J., R. E. Basher, B. B. Fitzharris, J. E. Hay, P. D. Jones, J. P. Macheigh, and I. Schmidely-Leleu, 1995: Climate trends in the south-west Pacific. Int. J. Climatol., 15, 285-302.

Seager, R., N. Naik, and G. A. Vecchi, 2010: Thermodynamic and dynamic mechanisms for large-scale changes in the hydrological cycle in response to global warming. J. Climate, 23, 4651-4668.

Trenberth, K. E., 1976: Spatial and temporal variations of the southern oscillation. Quart. J. Roy. Meteor. Soc., 102, 639-653.

Vincent, D. G., 1994: The South Pacific convergence zone (SPCZ): A review. Mon. Wea. Rev., 122, 1949-1970.

von Storch, H., H. van Loon, and G. N. Kiladis, 1988: The Southern Oscillation. Part VIII: Model sensitivity to SST anomalies in the tropical and subtropical regions of the South Pacific convergence zone. J. Climate, 1, 325-331.

Wang, Y., and Coauthors, 2008: Millennial- and orbital-scale changes in the East Asian monsoon over the past 224,000 years. Nature, 451, 1090-1093.

Widlansky, M. J., P. J. Webster, and C. D. Hoyos, 2011: On the location and orientation of the South Pacific convergence zone. Climate Dyn., 36, 561-578, doi:10.1007/s00382-010-0871-6.

, A. Timmermann, K. Stein, S. McGregor, N. Schneider, M. H. England, M. Lengaigne, and W. Cai, 2013: Changes in South Pacific rainfall bands in a warming climate. Nat. Climate Change, 3, 417-423, doi:10.1038/nclimate1726.

Wirrmann, D., S. H. Eagar, M. A. Harper, É. Leroy, and A.-M. Sémah, 2011: First insights into mid-Holocene environmental change in central Vanuatu inferred from a terrestrial record from Emaotfer Swamp, Efate Island. Quat. Sci. Rev., 30, 3908-3924.

Wyrwoll, K.-H., Z. Liu, G. Chen, J. E. Kutzbach, and X. Liu, 2007: Sensitivity of the Australian summer monsoon to tilt and precession forcing. Quat. Sci. Rev., 26, 3043-3057.

Xie, P., and P. A. Arkin, 1997: Global precipitation: A 17-year monthly analysis based on gauge observations, satellite estimates, and numerical model outputs. Bull. Amer. Meteor. Soc., 78, 2539-2558.

Xie, S.-P., C. Deser, G. A. Vecchi, J. Ma, H. Teng, and A. T. Wittenberg, 2010: Global warming pattern formation: Sea surface temperature and rainfall. J. Climate, 23, 966-986.

Zeng, N., D. Neelin, and C. Chou, 2000: A quasi-equilibrium tropical circulation model-Implementation and simulation. J. Atmos. Sci., 57, 1767-1796.

Zhao, Y., and S. P. Harrison, 2012: Mid-Holocene monsoons: A multi-model analysis of the inter-hemispheric differences in the responses to orbital forcing and ocean feedbacks. Climate Dyn., 39, 1457-1487. 